\title{
Em busca de "elos perdidos": projeto de assentamento e modos de identificação entre trabalhadores rurais assentados ${ }^{1}$
}

\author{
Rosemeire Aparecida Scopinho \\ Departamento de Psicologia da Universidade Federal de São Carlos
}

\begin{abstract}
Diante das transformações do mundo do trabalho rural, a organização de assentamentos rurais com base na agroecologia e no associativismo aparece como possibilidade para garantir a reprodução social dos trabalhadores rurais. Que caminhos percorrem esses sujeitos no traçado de suas vidas ao procurem atender tanto as exigências formais dos projetos de assentamento, quanto as suas necessidades de sobrevivência? $\mathrm{O}$ artigo trata essa questão a partir de um recorte específico: o de refletir sobre os motivos, os critérios e os valores que informaram a configuração da estrutura organizativa - a formação dos núcleos de trabalhadores - no momento da legalização de um determinado assentamento. Entendendo identidade como preparação e confrontando informações obtidas por meio de análise documental, da realização de observações diretas e de entrevistas individuais e coletivas, analisei o processo de nucleação considerando as características do projeto de assentamento e as dos trabalhadores rurais assentados e procurando perceber a existência de prováveis relações com os sentidos atribuídos pelos trabalhadores à cooperação.
\end{abstract}

Palavras-chave: Trabalho rural, Cooperação, Modos de identificação, Assentamento rural.

\section{Searching for the "lost links": settlement project and identification ways amongst settled rural workers}

In view of the transformations of the rural labor world, the organization of rural settlements based on agro-ecology and associativism surges as a possibility to ensure the social reproduction of rural workers. What are the ways those individuals follow when designing their lives, trying to meet the requirements of settlement projects as well as survival needs? This article discusses that issue, starting from a specific assumption: understanding the reasons, criteria and values which informed the workers about the organizational structure configuration - the formation of groups of workers - at the moment of legal constitution of a determinate settlement. By understanding identity as a preparation process and by cross-checking information obtained through document analysis, and carrying out direct observations and collective and individual interviews, I analyzed the dynamics of the nucleation process considering the characteristics of the settlement project as well as the settled rural workers', and trying to understand the existence of probable relations with the meanings attributed to cooperation by the workers.

Keywords: Rural work, Cooperation, Identification ways, Rural settlement.

$\mathrm{N}$ o Brasil, não é de hoje que as transformações típicas do mundo do trabalho contemporâneo já não se restringem ao cenário urbano e industrial. Especialmente nas últimas décadas, quando a produção rural incorporou um conjunto e inovações tecnológicas e organizacionais e com elas as consequências sócio-ambientais do nosso tempo, a preservação ambiental e as condições de sobrevivência dos trabalhadores rurais colocam-se como questões sociais preocupantes. Se o desemprego tecnológico e a falta de acesso aos meios para produzir surgem, cada vez mais, como tendências inexoráveis, os movimentos sociais e outros segmentos da sociedade voltam-se para a busca de alternativas e o Estado tem procurado institucionalizálas. A reforma agrária e a organização de assentamentos rurais com base na agroecologia e no associativismo aparecem como possibilidades para garantir a reprodução social desses trabalhadores. 
Nesse campo, as experiências organizativas desenvolvidas pelo MST (Movimento dos Trabalhadores Rurais Sem Terra) têm sido estudadas em diferentes áreas do conhecimento, especialmente nas ciências humanas e sociais. Se os estudos sobre as diferentes modalidades de cooperação e de cooperativas que se constituem nos assentamentos rurais não permitem desconsiderar o seu potencial na solução de problemas relacionados ao êxodo rural e à miséria que atinge esses trabalhadores, os quais declaram haver melhorias reais em relação à condição e ao modo de vida anterior, também não permitem visualizar transformações significativas nos problemas estruturais do mercado de trabalho rural e na atual dinâmica econômica da pequena agricultura familiar. Na prática, permanecem as dificuldades econômicas, porque crescem as inúmeras barreiras impostas pelo mercado e persiste a crônica insuficiência das políticas públicas de créditos, subsídios, assistência técnica e comercialização, entre outras, para a pequena produção agropecuária. Essas dificuldades combinam-se com aquelas da esfera intersubjetiva e política, em parte condicionadas pelas heranças culturais trazidas do assalariamento e pela falta de experiência dos trabalhadores com outras formas de organizar e realizar o trabalho. A complexa somatória dessas diferentes ordens de dificuldades concretas, que em cada caso articula-se de modo específico, e o fato de ser o associativismo formal uma condição sine qua non para que o Estado conceda a posse da terra e o acesso aos recursos de crédito e a outros direitos sociais garantidos por lei aos que estão na condição de assentados, faz surgir em cada cabeça uma sentença a respeito do que significa ser trabalhador rural assentado.

Coloca-se o problema de compreender que caminhos percorrem esses sujeitos no traçado de suas vidas ao procurarem atender tanto as exigências formais dos projetos de assentamento, quanto as suas necessidades de sobrevivência. Compreender os mecanismos de construção e as contradições desse percurso pode ser um caminho possível para o entendimento da própria subjetividade e identidade social desses trabalhadores.

A questão é complexa e tem sido abordada sob diferentes enfoques e perspectivas teórico-metodológicas no campo das ciências humanas e sociais. Se, para Oliveira (1996), as cooperativas organizadas pelo MST podem representar uma espécie de "contra-poder cooperativo", constituindo espaços de reação à concentração de poder e renda provocada pela modernização da agricultura brasileira, para Zimmermann (1994), a evasão dos associados é uma realidade inegável e os principais fatores que influenciam a dissolução dos grupos são a não equivalência da força de trabalho, as diferentes trajetórias de vida, a hierarquização e a subordinação das atividades de alguns grupos. D'Incao e Roy (1995) entenderam que os interesses nos acampamentos são homogêneos porque está em jogo a conquista da terra; nos assentamentos as singularidades afloram, cada família formula um projeto próprio e o MST enfrenta o desafio de articular o seu projeto de cooperação com os dos assentados. No processo de articulação, a aprendizagem da democracia e do interesse coletivo constrói-se no encontro e na negociação cotidiana dos interesses individuais. Na mesma direção, Romano (1995) mostrou que há um choque entre os valores do MST e os da maioria dos assentados. Nos assentamentos, inicialmente, evidencia-se a dimensão cooperativa e comunitária e depois afloram os conflitos da vida cotidiana, deflagrados pela constatação das divergências: de um lado, o interesse das lideranças de homogeneizar e mostrar as vantagens da cooperação segundo o MST e, de outro lado, o interesse dos assentados que, por forças da cultura, desejam controlar o espaço. Para Pilatti (1996), entre os assentados, os interesses são mais econômicos do que políticos. A participação é simbólica porque eles têm medo de serem expulsos do grupo por discordarem ou criticarem o seu funcionamento. ${ }^{2}$

Desde 2003, eu venho estudando o processo organizativo do Assentamento Sepé Tiaraju ${ }^{3}$ - localizado na região de Ribeirão Preto, SP -, procurando compreender como se

2 Ver também Rosim (1997), Carvalho (1999), Fernandes (1999), Justo (2005), entre outros importantes.

3 O assentamento é resultado da ocupação da Fazenda Santa Clara, antiga Usina Nova União, organizada pelo MST em 17 de abril de 2000. Em agosto de 2003, o Incra comprou a área de 790 hectares do governo do Estado de São Paulo e, em 20 de setembro de 2004, a Portaria n $\mathrm{o} 46$ do Incra oficializou o processo de assentamento de 80 famílias. 
realizam os princípios organizativos do MST e os processos culturais e ideológicos que sustentam as representações e as práticas dos trabalhadores rurais assentados, quando se trata de organizar o trabalho e as outras dimensões da vida cotidiana de modo cooperado e agroecológico. Neste artigo, tratarei a questão a partir de um recorte específico ${ }^{4}$, que consiste em refletir sobre os motivos, critérios e valores que informaram a configuração dos núcleos de famílias para compor a estrutura organizativa do assentamento no momento da oficialização do projeto. Este é um momento decisivo e crucial na trajetória de demandantes de terras que almejam constituírem-se como trabalhadores rurais assentados porque a legalização da ocupação, teoricamente, permite que se criem as condições objetivas para recomeçar a vida, de um modo diferente e melhor que o anterior; os núcleos de famílias são as instâncias básicas de decisão nas quais o planejamento da ocupação legal e definitiva do território deve ocorrer. Sem desconsiderar os múltiplos fatores ${ }^{5}$ que condicionam a sobrevivência e a permanência dos trabalhadores nos assentamentos rurais, pretendo neste artigo discutir, a partir do caso analisado, o que levou os trabalhadores, marcados por uma grande diversidade de origens, trajetórias, expectativas e representações, no momento da legalização do assentamento, a aglutinarem-se em torno de um projeto cooperado e agroecológico definido a partir de um acordo estabelecido, na época, entre o MST e o Estado. Trabalharei com a ideia de que, naquele momento, os trabalhadores criaram modos de identificação para constituir as estruturas organizativas necessárias à formalização do assentamento, modos estes que procuraram resgatar os elos comunitários típicos da sociedade rural brasileira tradicional ${ }^{6}$, o que tanto vinha de encontro com as diretrizes organizativas do MST e do Incra (Instituto Nacional de Colonização e Reforma Agrária), quanto reforçava algumas relações estabelecidas durante a fase de acampamento, criando o consenso necessário para garantir a posse da terra.

Bauman (2003) contribui para pensar essa questão ao discutir as ambiguidades do conceito de comunidade e estabelecer a distinção entre comunidade ética - cujo entendimento entre os membros é natural e compartilhado, ponto de partida (e não de chegada) para a união, a despeito de todos os fatores que possam contribuir para a separação - e comunidade estética cuja natureza superficial e transitória dos laços torna-os pouco duradouros e não cria entre seus membros uma rede de responsabilidades éticas e de compromissos de longo prazo. Estas são produtos dos tempos atuais, cuja velocidade das mudanças impõe um ritmo também muito rápido no modo como os sujeitos constroem vínculos por meio dos quais eles identificam-se e mantém-se como grupo organizado em torno de um determinado projeto de vida e de trabalho. O autor define identidade como algo que "(...) só nos é revelada como algo a ser inventado, e não descoberto, como alvo de um esforço, 'um objetivo' (...)” (Bauman, 2005, pp. 21-22). Nesse sentido, identidade é preparação, identificar-se com “(...) significa dar abrigo a um destino desconhecido que não se pode influenciar, muito menos controlar. Assim, talvez seja mais prudente portar identidades (...) como um manto leve pronto para ser despido a qualquer momento" (pp. 36-37). Em suma, identidade está sendo entendida aqui como produto da relação que o sujeito estabelece, em um determinado tempo e espaço, com as estruturas sociais às quais ele está vinculado.

4 Outras dimensões dessa problemática, tal como ela se apresenta no estudo de caso em questão, estão sendo exploradas no projeto Relações de trabalho, condições de vida e subjetividade: entre o trabalho dividido e o trabalho em cooperação (Fapesp, Programa Jovem Pesquisador) e no sub-projeto A cooperação e a formação da identidade dos trabalhadores em assentamentos rurais (CNPq, Edital $\mathrm{n}^{\circ}$ 50/2006).

5 Desde as condições naturais (tamanho dos lotes, tipo de terra, abundância de água); a existência de política agrícola voltada para os pequenos produtores; as demandas e as condições do mercado regional e local; as forças políticas pró ou contra a reforma agrária no entorno do assentamento; o apoio de redes societárias recebido durante a ocupação; a experiência dos assentados com as atividades agropecuárias e outras; as condições de acesso às tecnologias de produção e de oferta de assistência técnica e extensão rural até a adequação da região aos costumes e às tradições culturais das famílias, entre outros possíveis.

6 De acordo com Cândido (1971), Queiroz (1973), entre outros, formada por agrupamentos de famílias com forte sentimento de autonomia e pertença a uma localidade, unidas por vínculos de parentesco e vizinhança que sustentam práticas religiosas e econômicas baseadas na reciprocidade. 
Para elaborar este artigo, confrontei informações obtidas por meio de análise bibliográfica e documental, de observações diretas e de entrevistas individuais e coletivas realizadas entre 2003 e 2005, tempo em que, sistematicamente, eu acompanhei o processo organizativo do assentamento utilizando a convivência e o diálogo como estratégias para conhecê-lo (L'Estoile \& Sigaud, 2006; Withaker, 2002). Para compreender a questão proposta, não se deve perder de vista os condicionantes estruturais que permeiam as relações entre os sujeitos, no caso, o processo econômico e político global que faz (ou não) da reforma agrária uma estratégia de luta social pela melhoria das condições de trabalho e de vida na região de Ribeirão Preto. Lembrando Bourdieu (1997), é necessário fazer um esforço para entender o sujeito desde onde ele se encontra na estrutura social. Assim, analisei a dinâmica do processo de nucleação considerando as características do projeto de assentamento, o perfil sociocultural dos trabalhadores rurais assentados e procurei perceber a existência de prováveis relações com os sentidos atribuídos pelos trabalhadores à cooperação.

\section{Um projeto e os seus construtores}

Pensar o assentamento e o assentado requer considerar a definição dada pelos órgãos oficiais $^{7}$ do Estado encarregados da implantação das políticas públicas relativas ao II Programa Nacional de Reforma Agrária. A definição é técnica e burocrática: estamos diante de uma área de terra e de seus ocupantes, beneficiários de políticas públicas, portadores de registro e cadastro nos sistemas informatizados e integrados ${ }^{8}$.

Para os movimentos sociais, um assentamento é uma construção resultante da luta social pela melhoria das condições de vida no campo, território de resistência onde pode existir uma possibilidade de construção de um outro, ou melhor, modo de viver. $\mathrm{O}$ assentado é o sujeito dessa construção.

Com base na experiência acumulada em mais de vinte anos de existência, o MST indica o que deve ser levado em conta na organização dos chamados "novos assentamentos" para que eles se tornem espaços de relações sociais. Um importante momento do processo organizativo é o da demarcação dos lotes, porque é quando se define a geografia do assentamento: a localização dos espaços individuais e coletivos, as áreas de reserva e de preservação ambiental, de produção, de moradia, estradas e áreas de uso comunitário (escolas, postos de saúde). O MST denuncia que, geralmente, isso tem sido feito a partir de critérios técnicos e sem levar em conta as necessidades e as expectativas dos acampados, reproduzindo um modelo de ocupação do espaço rural que contribui para o isolamento social. Essa não é uma questão estritamente técnica porque depende de decisões que são tomadas pelas pessoas em relação a onde morar e trabalhar, com quem se associar para trabalhar. Dada a importância da participação do trabalhador rural nessas decisões, as famílias devem se organizar em grupos processo chamado de nucleação -, o que define os seus lugares na estrutura organizativa, ou seja, nas instâncias onde acontece o processo decisório.

\footnotetext{
7 Enquanto o assentamento é: "Unidade territorial obtida pelo programa de Reforma Agrária do Governo Federal, ou em parcerias com Estados ou Municípios, por desapropriação; por arrecadação de terras públicas; aquisição direta; doação; reversão do patrimônio público ou por financiamento de créditos fundiários, para receber em suas várias etapas, indivíduos selecionados pelos programas de acesso à terra"; o assentado é: "o candidato inscrito que, após ter sido entrevistado, foi selecionado para ingresso ao Programa de Reforma Agrária, sendo-lhe concedido o direito do uso de terra identificada, incorporada ou em processo de incorporação ao Programa" (Portaria MDA no 80 de 24/04/2002).

8 O Sipra (Sistema de Informações de Projetos de Reforma Agrária) reúne um conjunto de informações sobre os projetos de assentamento e seus beneficiários.

9 "Novos assentamentos" porque as orientações são produto de uma avaliação realizada pelo MST, entre 2000 e 2002 , dos resultados organizativos obtidos nos assentamentos desde os anos 1980 . Em síntese, o balanço apontava que os assentamentos estavam longe de serem espaços de relações sociais no sentido definido acima, não passavam de objeto da política social compensatória implementada pelos governos no período, sendo necessário rever a relação com o Estado (Carvalho, 2005).
} 
Os núcleos são definidos como estruturas organizativas informais que reúnem, no máximo, vinte famílias e constituem a instância básica de gestão do assentamento, são coordenados por um homem e uma mulher (para ter a inserção e o "olhar" feminino no processo) e cumprem a finalidade de garantir a participação ampla na construção dos consensos e evitar o "assembleísmo". Regidos pelo princípio da direção coletiva, podem ou não institucionalizarem-se na forma de associações, cooperativas ou outra forma de empresa social. Dada a importância da manutenção das relações já estabelecidas durante o período de acampamento, os critérios de nucleação devem ser definidos pelas famílias, devendo o sorteio da localização dos lotes respeitar o existente para evitar a desagregação e facilitar a cooperação. Além dessas orientações básicas, destacam-se outros elementos que facilitam a sociabilidade: a participação comunitária na organização da infra-estrutura e dos serviços internos no assentamento (escola, cuidados com a saúde, transporte, comércio), a religiosidade, o cuidado com as praças, parques infantis, os espaços de manifestação artística e cultural e de preservação da memória comunitária (Associação Nacional de Cooperação Agrícola, 2002).

A partir dessas orientações gerais, foram formuladas propostas específicas para as diferentes regiões do país, de acordo com sua realidades locais. A proposta formulada pela CCA (Cooperativa Central dos Assentados do Estado de São Paulo, denominada Comuna da Terra) está fundamentada na constatação empírica dos dirigentes de que neste estado os acampamentos rurais mais recentes caracterizam-se pela localização em áreas de terra relativamente pequenas e próximas aos grandes centros urbanos. O acampado é, geralmente, o assalariado rural que perdeu emprego devido à intensificação da mecanização agrícola nos anos de 1990. O projeto de assentamento deve romper com o modelo agropecuário tecnicista e especializado, que provocou impactos sócio-econômicos ambientais negativos, e promover a "re-campesinação", ou seja, o retorno do trabalhador rural ao campo para produzir com base nos princípios da agroecologia, utilizando trabalho familiar e autogestionário e destinando a produção para o mercado interno e popular. Aproveitando as características da população que demanda terra, a proposta visa conciliar o desenvolvimento de atividades agrícolas com não agrícolas para solucionar problemas de emprego no campo e na cidade. Visa ainda criar condições para o desenvolvimento sócio-cultural, procurando romper com a dicotomia campocidade e superar os estereótipos que identificam o homem do campo com o arcaísmo e a ignorância (Concrab, 2004; Matheus, 2003).

Em suma, a proposta do MST para os assentamentos é criar comunidades onde se possa trabalhar e viver com autonomia: “(...) os assentamentos não são apenas uma unidade de produção. Mas, acima de tudo, são um núcleo social onde as pessoas convivem e desenvolvem um conjunto de atividades comunitárias na esfera da cultura, lazer, educação, religião etc (...)" (Confederação das Cooperativas de Reforma Agrária do Brasil, 1998, p. 26).

Quando o Incra comprou a área da Fazenda Santa Clara e iniciou o processo de assentamento das famílias, também trouxe consigo uma proposta de modelo de assentamento. A compra da área foi objeto de divergência no interior daquele órgão. Baseados em outras experiências desenvolvidas na região ${ }^{10}$, os que discordavam da compra alegavam que: 1) devido à localização, o preço da terra era muito alto; 2) os demandantes não tinham perfil de pequenos produtores rurais; 3) a proximidade do assentamento a grandes centros consumidores, por um lado, facilitaria o escoamento da produção, mas, por outro, implicaria em enfrentar a forte concorrência no mercado agropecuário, o que poderia acarretar o fracasso do projeto, o endividamento dos assentados e, consequentemente, a evasão ou o arrendamento das terras para as usinas da região, tornando-as alvo da especulação imobiliária.

A compra somente foi efetivada depois de ter sido firmado um acordo sobre a modalidade de projeto a ser implantado na área, que deveria ser do tipo PDS (Projeto de 
Desenvolvimento Sustentável) ${ }^{11}$, ou seja, "uma modalidade de assentamento de interesse sócio-econômico-ambiental, destinado às populações que já desenvolvem ou que se disponham a desenvolver atividades de baixo impacto ambiental, baseado na aptidão da área" (Incra, 2000, p. 19), adaptado à realidade regional. As condições essenciais colocadas pelo Incra para oficializar o PDS Sepé Tiaraju foram: conceder o título de posse (e não de propriedade) da terra para evitar a venda e o arrendamento; produzir de modo cooperado e agroecológico para recuperar a área degradada pela monocultura da cana; criar uma empresa social para receber os recursos financeiros e realizar a prestação de contas para o Estado; formar um comitê gestor do assentamento composto por representantes dos poderes públicos estaduais e municipais, dos assentados, de organizações não governamentais locais e do Incra.

Essas condições, em linhas gerais, não eram muito diferentes do que já vinha sendo proposto pelo MST desde a década de oitenta. A propósito, as propostas do Estado para organizar assentamentos têm sido, em linhas gerais, construídas ao longo desses anos com base nas experiências desenvolvidas pelos movimentos sociais, o que tanto reafirma o protagonismo destes, quanto a capacidade que tem o Estado de institucionalizar as experiências populares.

Se o projeto de assentamento, fruto de um acordo, configurou-se como um misto de comunidade rural acrescida da ideia de sustentabilidade contida no PDS, os seus construtores eram portadores de uma história cuja característica marcante é a diversidade sócio-cultural. Em geral, eram migrantes que vieram para São Paulo entre os anos 1970 e 1990 para trabalhar temporariamente nas agroindústrias de cana ou laranja. Os entrevistados residiram em 340 diferentes cidades. Eles eram originários de 106 cidades situadas em 15 diferentes estados brasileiros, das quais 37 (35\%) estão situadas no interior do próprio estado de São Paulo. As demais cidades de origem estão localizadas, especialmente, em Minas Gerais (18\%), Paraná (16\%), Bahia (11,4\%), Pernambuco (5,7\%), além de vários outros estados nordestinos. Entre deixarem as origens e serem assentados, os trabalhadores passaram por 234 cidades localizadas em 20 diferentes estados, chegando um deles até o Paraguai. Migraram, principalmente, pelas cidades do interior do estado de São Paulo (39\%), do Paraná (15,3\%), Bahia (8\%) Minas Gerais $(7,7 \%)$ e Pernambuco (6\%), o que reflete a dinâmica migratória do estado de São Paulo, como se verifica em Perillo e Perdigão (2005). Ocorre que, na década de 1990, intensas transformações espaciais, culturais, econômicas e sociais atingiram tanto o campo, quanto as cidades. O desemprego generalizado, aliado à ausência de alternativas de obtenção de renda e à omissão do Estado no que se refere à situação dos desempregados, obrigou essa população a sobreviver precariamente do trabalho informal, nas periferias das chamadas "cidadesdormitório", de bóias-frias.

É notável ainda a diversidade de experiências de trabalho. Ao longo do itinerário, eles nem sempre conseguiram manter a rota profissional e transformaram-se em vários outros tipos de trabalhadores para sobreviver. São experiências marcadas pelo desenvolvimento de atividades em diversos setores e ramos da economia formal e informal. Na cidade, prestaram serviços, geralmente, no âmbito doméstico tais como: acompanhante de idosos, babá, cozinheira, costureira, dama de companhia, diarista, dona de casa, eletricista, empregada doméstica, encanador, faxineira, lavadeira e passadeira de roupas, trabalhos domésticos em geral, entre outros; na indústria foram auxiliares de produção em diversos setores da economia (desde indústrias alimentícias até de chapéu); no comércio foram, principalmente, vendedores, fixos ou ambulantes, de diversos produtos e em diferentes contextos. No campo, foram prestadores de serviços gerais (em 34 tipos de culturas diferentes) e de serviços especializados,

11 O PDS nasceu da discussão empreendida por técnicos do MMA (Ministério de Meio Ambiente, Conselho Nacional dos Seringueiros), do Centro Nacional de Populações do Ibama (Instituto Brasileiro de Meio Ambiente e Recursos Naturais Renováveis) e do Incra para atender aos interesses e anseios do governo, dos movimentos sociais e dos demandantes de terras para conciliar o assentamento humano e a preservação de áreas de interesse ambiental como a Amazônia, no sentido de promover o desenvolvimento sustentável. Uma das principais idealizadoras do PDS foi a missionária norte-americana Dorothy Mae Stang, assassinada em 12 de fevereiro de 2005, na cidade de Anapú, PA, supostamente, por defender os direitos humanos e a preservação ambiental em áreas de conflitos agrários na região amazônica. 
como boiadeiro e tratorista, além de "chapas"12 e fazedores de "bicos". Desempregado foi condição frequentemente mencionada. O fato importante é que essas atividades não requerem qualificação formal e indicam a inserção dos trabalhadores em relações e condições de trabalho precárias, realizadas sem o mínimo de garantia do cumprimento da legislação trabalhista e social.

Em meio às diferenças, o fato de serem portadores da doença do desenraizamento, no sentido dado por Weil (1996), e de trajetórias sociais precárias foi o que levou os trabalhadores a aderirem à luta social em favor da reforma agrária. As famílias tinham uma composição muito variada, desde as numerosas (mais de oito pessoas) até os "sozinhos", pessoas que, no processo de migração e nas andanças empreendidas em busca de terra e emprego, separaram-se ou perderam contato com seus parentes. Eles eram, na maioria, do sexo masculino, alguns muito jovens, que experimentaram a condição de serem moradores de rua, que mantiveram ligações com o tráfico organizado de drogas como estratégia de sobrevivência e procuravam lidar com as consequências à saúde e com os agravos da dependência de drogas; outros, mais idosos, que a dependência crônica do uso de álcool havia separado do convívio familiar e excluído do trabalho. As mulheres, geralmente, estavam sozinhas por viuvez ou por separação do marido. $\mathrm{Na}$ época da oficialização do assentamento, havia uma expectativa comum: encontrar um lugar para ficar onde pudessem satisfazer as crônicas necessidades básicas de acesso à alimentação, moradia, segurança e reconstruir vínculos familiares perdidos no percurso da exclusão. Foram, justamente, essas características e expectativas que deram âncora à ideia de comunidade rural sustentável contida no projeto de assentamento.

\section{Critérios, motivos e valores subjacentes ao processo de nucleação}

Acampamentos e assentamentos definem-se por serem, respectivamente, ocupações não legalizadas e legalizadas do ponto de vista da propriedade da terra. Mais importante do que isso para o que eu pretendo discutir aqui é o fato de serem agrupamentos humanos marcados pela mudança e pela instabilidade nas relações sociais. Um acampamento é um campo provisório, precário e dinâmico, tanto porque os ocupantes podem ter que se transferir para outro lugar a qualquer momento com a chegada de liminares de reintegração de posse, quanto porque, ao longo do tempo, muitas famílias passam por ali. Para o MST, a condição essencial para ter acesso a um lote de reforma agrária é a vivência no acampamento, que é visto como uma espécie de escola preparatória para ser assentado, um espaço de ressocialização constituído por um conjunto de normas disciplinares, tendo em vista que o desafio dos que lá estão é reconstruir a vida a partir de uma outra lógica que não reproduza a condição anterior. Ao longo do processo, muitas famílias desistem pelos motivos mais diversos: os seus integrantes conseguem um emprego, resolvem migrar, um parente decide acolher ou, simplesmente, porque não se adaptaram às regras estabelecidas, ao convívio comunitário, às condições precárias; outras famílias optam por mudar para outro acampamento por livre e espontânea vontade ou porque são convidadas pelo MST ou pelo Estado para fazê-lo. Além das desistências, ocorre também o ingresso de novas famílias. Por exemplo, reconstruindo a história da ocupação do Assentamento Sepé Tiaraju, percebi que o número de famílias oscilou entre, no máximo, duzentas e, no mínimo, dezoito famílias. As andanças em busca de um "bom lugar para ficar" as fizeram perder documentos e os poucos objetos de uso pessoal e doméstico que possuíam.

No Sepé Tiaraju, a passagem do assentamento legal para o real foi acontecendo lentamente, processo que consistiu de muitas negociações e tomadas decisões em que a

12 "Chapa" é aquele trabalhador que, geralmente, instala-se em "pontos" situados às margens de rodovias nas proximidades ou nas vias de acesso das cidades à espera de caminhoneiros para os quais se oferece para prestar serviços de auxiliar de carregamento ou descarregamento de cargas na condição de diarista. 
demarcação dos lotes e a formação dos núcleos de famílias ocorreram simultaneamente, porque essas eram condições essenciais para acessar os créditos e outros recursos previstos em lei para desenvolver o projeto. Mesmo sem ter as garantias da posse legal, o assunto sempre foi objeto de debates entre os trabalhadores, constituindo os primórdios do planejamento da ocupação da área, que ora traduzia-se em avanços, ora em recuos do processo organizativo. Esse foi um processo sócio-educativo considerado importante pelos trabalhadores, porque ensaiou a participação, resgatou a autoestima, motivou, assim como possibilitou a criação de mecanismos de conhecimento mútuo e de identificação entre as pessoas, dimensões essenciais na construção de um projeto de coletividade.

Desde os tempos de acampamento, sempre existiram estruturas organizativas no Sepé Tiaraju: a coordenação geral e os Coletivos de Saúde, Educação, Cultura e Produção eram as principais instâncias de decisão. No início da ocupação, quando o número de acampados não passava de cinquenta, além dessas instâncias, foram criados dois núcleos de produção, o Zumbi dos Palmares e o Dandara, cujos membros, coletivamente, tanto trabalhavam para garantir o autossustento das famílias, quanto discutiam o projeto de ocupação da área. Esses núcleos originais funcionavam ao sabor da instabilidade característica do acampamento, ora organizando-se, ora desorganizando-se de acordo com as necessidades e interesses emergentes.

A oficialização e o anúncio do assentamento de oitenta famílias na área deu início à nucleação definitiva. Foram trazidas mais nove famílias do Acampamento Terra Sem Males (Campinas, SP) e vinte e cinco do Acampamento Mário Lago (Ribeirão Preto, SP) para completar as oitenta e formaram-se outros dois núcleos: o Paulo Freire e o Chico Mendes. Os Núcleos Zumbi e Dandara foram, em um primeiro momento, desfeitos para se refazerem misturando as famílias recém-chegadas com as que já se encontravam acampadas, procurando criar condições para facilitar a integração entre elas. Mas, as relações já estabelecidas entre as pessoas fizeram com que os núcleos originais mantivessem-se praticamente inalterados. Afinidade foi o critério organizativo seguido pelas famílias no processo de nucleação:

(...) se percebeu o seguinte: $90 \%$ do pessoal que era do Dandara ficou no Dandara; $95 \%$ do pessoal que era do Zumbi permaneceu no Núcleo Zumbi. Então acho que foi assim, foi afinidade, no final das contas foi afinidade esses núcleos aqui. (...) [por afinidade] dá mais certo porque conhecem a pessoa, convivem há muito tempo. Pode prever o que o outro vai fazer, dizer, como o outro quer conviver (membro do núcleo Zumbi, 16/04/2004).

Observei que a afinidade referida tanto se relacionava ao parentesco, quanto à amizade construída na convivência cotidiana por meio do diálogo, do respeito às regras tácitas e à organização existente no interior das famílias e nas relações de vizinhança e da ajuda mútua experimentada nos momentos de necessidade.

A nova nucleação não alterou a rotina dos núcleos Zumbi e Dandara. Os poucos ingressantes integraram-se na rotina de trabalho, de estudos e de discussões sobre o projeto de assentamento. O núcleo Zumbi agregava vinte e uma famílias e a afinidade existente entre os seus integrantes era sustentada por valores de natureza política. Além da experiência acumulada pelo tempo de convivência dos integrantes, o núcleo combinava de modo positivo a contribuição de lideranças que militavam no MST com outras que atuavam no âmbito das famílias. As vinte famílias do Dandara consideravam que a discussão realizada no âmbito do núcleo ajudava a planejar o trabalho e ainda servia para estreitar os laços de solidariedade e estabelecer o diálogo que consolidava as relações de vizinhança. Um importante elemento de identificação entre os componentes deste núcleo era o fato de que a maioria era adepta da igreja evangélica, sendo a afinidade, portanto, sustentada por valores de natureza religiosa. Um dos coordenadores do núcleo Dandara entendia que o assentamento é um ato divino e a cooperação é um talento inato, um sinal de respeito a Deus; outro membro assim expressou o seu sentimento de pertencimento e de orgulho em relação ao núcleo: 
(...) foi o primeiro a se organizar, os outros vieram olhando para a gente, como é que nós fazíamos. Então, a gente vem mostrando como a gente deveria fazer, o capricho. Eu pretendo, nós pretendemos deixar o núcleo... não dizer que ele vai ser o melhor, mas, pelo menos, dar um pouco de exemplo, de capricho, de zelo, eu estou muito feliz e hoje mais ainda porque eu sei que eu vou ficar aqui (membro do núcleo Dandara, 08/04/2004).

Os núcleos Paulo Freire e Chico Mendes foram formados a partir da integração das trinta e quatro famílias "estranhas" vindas de outros acampamentos e dos dissidentes do Zumbi e do Dandara e não havia clareza sobre que tipos de valores sustentavam os vínculos. O núcleo Chico Mendes tinha vinte famílias e era formado por uma parte dos que vieram do Acampamento Mário Lago, que se juntou aos dissidentes do Dandara e do Zumbi por discordarem da forma como foram conduzidas as primeiras experiências de produção coletiva. Os integrantes deste núcleo ainda esforçavam-se para diminuir as distâncias e integrarem-se ao assentamento, mas sofreram por muito tempo por estarem na condição de outsiders, no sentido atribuído por Elias e Scotson (2000).

O processo de integração de novas famílias foi, inicialmente, tenso. Se, de um lado, a entrada de novos elementos significava reforço, segurança e ampliação da capacidade de argumentação e luta, por outro, significava também ter que dividir os poucos recursos existentes para a alimentação, materiais para a construção de barracos, remédios, roupas, ferramentas e sementes, entre outros itens importantes. Significava, sobretudo, ter que rever decisões já consolidadas em função das novas necessidades e ideias trazidas pelos ingressantes. A rejeição também ocorria porque nem todos compreendiam que, pela determinação do Incra, a área comportava oitenta famílias. Entre os acampados, havia a expectativa de que quanto menor fosse o número de famílias, maior o tamanho do lote que cada uma receberia. Observei que houve um período de adaptação em que até a localização espacial dos novos barracos ficava separada dos já existentes. Com o tempo e com as inúmeras possibilidades de interação (reuniões e atividades coletivas) criadas pelo MST, o distanciamento diminuía e os grupos reorganizavam-se para incorporar os recém-chegados, que, aos poucos, adaptavam-se ao ritmo e acatavam as regras estabelecidas. Além das oportunidades de interação planejadas, a integração também foi possibilitada pela partilha espontânea do que os ingressantes traziam para o acampamento (alimentos, remédios, roupas, instrumentos de trabalho) ou dos alimentos que ali produziam.

O núcleo Paulo Freire tinha como característica fundamental uma fragmentação advinda, ao meu ver, do fato abrigar os que vieram do Acampamento Terra Sem Males e os dirigentes do MST que deveriam ser assentados na área, que somavam onze das dezenove famílias. A dinâmica de relacionamento dos membros desse núcleo era representativa do distanciamento existente entre os dirigentes e os assentados. A participação era desigual, havia um grande descompasso na forma de entender os processos porque, geralmente, os dirigentes tinham interesses e graus de politização diferenciados e não conseguiam conciliar a agenda da militância, sempre sobrecarregada, com a dos assentados, o que impossibilitava o diálogo e aumentava as distâncias. Mesmo quando o encontro era possível, a experiência da militância conferia uma força maior para a argumentação dos dirigentes e, por isso, influenciavam o processo de tomada de decisões.

A tensão entre ser militante e ser acampado ou assentado resulta da divisão social do trabalho existente nesses espaços. Ao militante era atribuída a responsabilidade de fazer a articulação política e a mediação entre a sociedade, o Estado e os acampados, o que requeria uma atuação fora dos assentamentos e impossibilitava-o, portanto, de participar das atividades produtivas dos núcleos. Ao assentado cabia produzir, executar o trabalho coletivamente planejado, o que o fazia sentir-se vítima da injustiça de ter que trabalhar pelos militantes e do estigma de ser trabalhador rural, socialmente visto como ignorante, "atrasado". Os militantes esforçavam-se para diminuir as diferenças: 
(...) quem trabalha na enxada, por exemplo, ele vê diferente uma pessoa que vai à cidade, mesmo que [a pessoa] vá à cidade para conquistar um projeto e trazer um monte de recursos para cá, mas não é visto isso. E não é culpa dele [de quem trabalha na enxada] também. Nós fomos criados assim. Eu tenho que tocar a enxada naquele morro, nem que seja pedra, eu tenho ido lá para mostrar para os outros que... [eu também trabalho com a enxada] (membro do núcleo Paulo Freire e militante do MST, 08/04/2004).

Os demais explicavam como ocorreu o distanciamento apontando que a responsabilidade sobre as decisões deveria transferir-se do MST para o núcleo, depois de oficializado o assentamento: “(...) o MST fazia valer suas opiniões enquanto era acampamento. Depois do assentamento, os núcleos é que são responsáveis pelas decisões" (membro do núcleo Paulo Freire, 08/04/2004). Esse trabalhador falava de um momento em que, para organizar o acampamento, os dirigentes do MST tiveram que definir as regras do jogo, até para manter a disciplina e convergir as diferentes contribuições e forças do grupo para obter a posse da terra. Ele apostava no funcionamento autônomo dos núcleos no futuro assentamento no qual (ele imaginava) os objetivos organizativos e os mecanismos de participação seriam diferentes e as dificuldades de outra ordem e natureza.

Se entre os membros dos núcleos Paulo Freire e Chico Mendes havia divergências, havia também um esforço coletivo no sentido de construí-los tal como foram construídos o Zumbi e o Dandara, cujos membros acumulavam convívio e experiências compartilhadas que facilitavam, minimamente, o acerto das diferenças. A diferença é que Zumbi e Dandara, talvez por serem os núcleos mais antigos, demonstravam um grau de coesão e capacidade de entendimento mútuo maior do que os núcleos Paulo Freire e Chico Mendes, construídos a partir integração das famílias "estranhas" ao Sepé Tiaraju, dos dissidentes e dos militantes.

Em todos os núcleos, o levantamento, a discussão e o encaminhamento de soluções para os problemas eram feitos por meio de reuniões, formais ou informais, que aconteciam na medida da necessidade, da importância e da urgência do assunto. Observei que havia um grande número de reuniões informais, realizadas na rua da agrovila, geralmente no final da tarde, ou em algumas moradias que funcionavam como pontos de encontro ${ }^{13}$. Não era costume formalizar as reuniões, em termos da existência de pauta, de horário para começar e terminar, mas elas ocorriam e causavam um intenso vaivém de informações cujo fluxo, dependendo do assunto e dos envolvidos, ora contribuía para solucionar impasses e construir consensos, ora acentuava ainda mais as diferenças. Os trabalhadores demonstravam capacidade de diálogo, embora nem sempre utilizada no sentido construtivo. Apesar das reuniões e da existência de mecanismos de tomada de decisão que envolvia vários níveis, momentos e instâncias, a comunicação nem sempre era clara, os próprios assentados identificavam ser esse o maior problema referindo-se a "forças que desmobilizam a organização dos núcleos". Um deles descreveu como elas atuavam:

(...) há os que falam mais, os que falam menos; há os que manipulam os mais fracos; não se respeita a assembleia que é a instância superior; há problemas de comunicação e transparência; toma decisões em nome do coletivo e não explica o porquê. É a rede de influências negativas que atrapalha o planejamento dos núcleos (membro do núcleo Zumbi e militante do MST, 16/08/2004).

Ocorre que, além das trinta e quatro famílias, muitas outras pessoas chegaram a partir do momento em que os lotes foram demarcados e ocupados definitivamente, as quais, por serem familiares dos estabelecidos, foram imediatamente incluídas nos núcleos de origem de suas famílias a partir do critério de parentesco. A chegada dos familiares e dos agregados gerava conflitos e dificuldades de integração, pois eles não acompanhavam o ritmo e não acumulavam

13 Um dos barracos era conhecido como a "Única”, em alusão a um bar existente no centro comercial de Ribeirão Preto, que é um tradicional ponto de encontro de antigos moradores, comerciantes e políticos da cidade, onde, sob o pretexto de tomar um cafezinho, fala-se de negócios, de política e de fatos do cotidianos. 
a experiência vivida no acampamento. Dessa forma, a oficialização do assentamento não significou a estabilidade das relações, pelo contrário, criou outras forças e novos movimentos que ora contribuíam para fortalecer, ora para enfraquecer alguns núcleos e famílias em detrimento de outras.

\section{Os modos de identificação e a cooperação}

O PDS Sepé Tiaraju tentou resgatar a ideia de comunidade rural sustentável, lugar onde as pessoas organizam-se por afinidade com base nas relações de parentesco e vizinhança para trabalhar e viver ajudando-se mutuamente, aproximando-se do modo tradicional de organização no mundo rural, tal como foram analisados por Cândido (1971) e Queiroz (1973), entre outros. O projeto conferiu certa ordem simbólica à dinâmica do processo de nucleação das famílias mas, na prática, os sentidos atribuídos pelos trabalhadores do Sepé Tiaraju à cooperação eram contraditórios, expressavam não só a percepção de vantagens de natureza econômicas, sociais e políticas, mas também as desvantagens em relação às diferenças individuais, ao controle e à dominação exercidos de outras formas. Fora do trabalho, a cooperação espontânea estava sempre muito presente no cotidiano das famílias, ampliando e dinamizando as formas e as redes de convivência, favorecendo a resistência e a permanência no assentamento. Embora resistissem à institucionalização da cooperação, eles não puderam fugir do associativismo, condição imposta pelo Estado para torná-los assentados e, por força das circunstâncias, adotaram um modelo de associativismo formal, no qual o trabalho não é central e a cooperação se dá apenas no plano da compra de insumos e da comercialização dos produtos. Caracterizou-se um tipo de cooperativismo tradicional existente no mundo do trabalho rural brasileiro há mais de um século que, embora exista formalmente como estrutura organizativa horizontal, reproduz as relações de poder típicas das estruturas hierarquizadas e heterogeridas (Scopinho, 2007).

Assim, no projeto, os núcleos seriam os embriões de uma entidade coletiva, que abarcaria as oitenta famílias, denominada "associação-mãe" porque, futuramente, eles poderiam formalizar-se como "associações-filhas". Embora fossem estruturas independentes entre si, em termos organizativos e até pela localização espacial dentro do assentamento, os núcleos teriam autonomia relativa. Para ilustrar como dariam-se as conexões entre essas diferentes estruturas, o coordenador do assentamento comparou a relação entre elas como se fosse um "rio (mãe) que tem braços (filhas)", explicando que essa foi uma estratégia definida com base em dois motivos: "(...) um, facilita a organização porque vinte é menor que oitenta e, dois, se quebrar, não quebra todo mundo". Nesse assentamento, a identidade de trabalhador rural assentado parece estar construindo-se por meio de uma diversificada constelação de formas organizativas, formais e informais - núcleos e subnúcleos de famílias, comissões para lidar com temas específicos (saúde, educação, cultura), pequenas associações vinculadas a uma associação maior - que nem sempre estão diretamente ligadas às relações de trabalho propriamente ditas.

Se o motivo que levou à organização dos núcleos de famílias foi a necessidade imposta de aderir ao associativismo para tornar real o projeto de assentamento, ao definirem modos de identificação baseados em critérios de afinidade, os trabalhadores buscavam recuperar os "elos" comunitários "perdidos" ao longo da trajetória de vida e trabalho e reconstruir um mundo no qual fosse possível satisfazer as suas crônicas necessidades de enraizamento. Sem dúvida, eles reconstruíram a comunidade ideal naquele momento em que já não podiam suportar as angústias da espera e predominavam expectativas positivas em relação ao assentamento, as necessidades eram muitas e não já estavam sendo satisfeitas com base na economia de trocas sustentada pela cooperação espontânea e pelos contatos esporádicos com o mercado. Mas, no decorrer da implantação do projeto, o modelo organizativo que foi importante para legalizar o 
assentamento revelou a insuficiência das políticas públicas e a burocracia dos mecanismos de controle impostos pelo Estado, o distanciamento entre os ideais e os interesses da militância e as necessidades dos diferentes núcleos, o peso das heranças socioculturais trazidas pelos trabalhadores foram alguns elementos que contribuíram para a fragmentação, tornada cada vez mais explícita.

Os problemas surgiram, concretamente, com a vinda dos primeiros (e parcos) recursos que os obrigou a desenvolverem, coletivamente, os planos de produção que, de fato, lhes dariam acesso aos créditos e a outros direitos. Eles se viram diante da necessidade de atender às exigências colocadas pela burocracia estatal e pelo mercado, de gerenciar de modo eficaz e eficiente os recursos investidos, tornando os resultados quantitativamente mensuráveis e socialmente visíveis - e politicamente utilizáveis para justificar a forma como o Estado tem feito (ou não) a reforma agrária. Para compreender essa dificuldade, além dos elementos em relação ao perfil dos trabalhadores, é importante lembrar que o Sepé Tiaraju localiza-se em uma região que tem a economia centrada na agricultura considerada desenvolvida, onde a "modernidade" tem sido entendida como movimento de incorporação de novas tecnologias, que está presente e é cada vez mais acelerado tanto na cidade, quanto no campo. Falar de assentamentos rurais naquela região significa falar de sujeitos e de comunidades que convivem em meio a relações econômicas e sociais complexas. Nesse contexto, a economia dos assentamentos permanece nas bordas, como obra de excluídos que dela participam, operando no limite da subsistência ou marginalmente integrados na lógica dos grandes.

As condições de realização do trabalho no assentamento não favoreciam o desenvolvimento da cooperação autogestionária como forma de superar esses impasses. Pelo contrário, a falta de capital, de infraestrutura (principalmente água) e de orientação técnica para realizar a agroecologia e as restrições impostas pelo TAC (Termo de Ajustamento de Conduta ${ }^{14}$ condicionavam um jeito de fazer a economia do assentamento funcionar que levava os assentados a "dar uns pulos" para sobreviver. O associativismo era considerado como uma espécie de máquina de captação de recursos e não como instrumento de pressão política contra o Estado e o mercado. O emprego temporário e informal - "fazer bico" ou "dar uns pulos" - era uma forma de trabalho muito utilizada para superar dificuldades econômicas. Existia um mundo do trabalho, agrícola ou não, muito ativo e intenso dentro do assentamento que se vinculava, direta ou indiretamente, com os municípios do entorno. "Quando eu tenho uma conta para vencer eu deixo as coisas daqui, eu trabalho dez, quinze dias, pego o dinheiro e pago".

Em 2008, eu fiz um levantamento das outras fontes de renda existentes entre os quatorze trabalhadores ligados à única associação que havia sido formalizada no assentamento e constatei que três deles contavam com a aposentadoria de familiares; dois trabalhavam como pedreiros e serventes de pedreiro, um como tratoristas (dentro e fora do assentamento), a esposa de um associado trabalhava como faxineira (em Ribeirão Preto) e um associado montou um pequeno bar no seu lote, onde revendia bebidas em geral e petiscos. $\mathrm{O}$ próprio projeto de implantação do assentamento gerava possibilidades de remuneração para os assentados ao realizar as obras de infraestrutura a partir da organização de frentes de trabalho para construir casas, estradas e demais instalações. No dia-a-dia, observei um intenso movimento comercial, que envolvia os assentados entre si e a vizinhança, que negociavam desde carros, ferramentas e implementos, animais, sementes, adubos, materiais de construção, entre outros itens, até a compra e venda de serviços de construção de casas, de cercas, de instalações elétricas, de consertos em geral, entre outros. Era também prática comum entre os assentados a contratação de diaristas para realizar o trabalho mais pesado na lavoura. Ou seja, eles tanto eram contratados, como contratavam. Configurava-se no assentamento um mercado de trabalho

14 Esse TAC (inquérito civil no 18/2007) foi um compromisso assumido entre o Ministério Público, a Superintendência do IncraSP e os trabalhadores assentados, que envolve a instalação de infra-estrutura e saneamento básico, o desenvolvimento de atividades sócio-culturais e a recuperação ambiental da área com o desenvolvimento de produção agrícola conservacionista no assentamento. O problema é que o Incra não ainda ofereceu plenas condições para cumprir o acordo e o Ministério Público ameaça retirar os lotes dos assentados que não o cumprirem. 
informal onde as pessoas "se viram”, “dão uns pulos”, táticas de sobrevivência desenvolvidas para investir no lote e sustentar a família no assentamento.

Nesse sentido, a situação de trabalho atual não era muito diferente das trajetórias de trabalho e vida que traziam consigo. A precariedade dos vínculos, a incerteza e a pobreza da remuneração permaneciam, apenas mudaram de endereço: das periferias urbanas para o assentamento. Uma diferença substancial entre uma condição e a outra diz respeito à certeza de ter endereço fixo e um pedaço de terra para produzir alimentos e manter uma economia de subsistência. Assim, os núcleos de famílias deixaram de ser referência organizativa e passaram a ser apenas referência espacial de endereço dentro do assentamento.

No momento da legalização, os assentados traziam representações idealizadas da volta à terra como sendo um passo na direção da autonomia, o que ainda não se confirmou na vida real do assentamento, onde, junto com o andar inseguro da nossa história lenta, como refere Martins (1994), é imperativo acompanhar o ritmo de mudanças imposto pela proximidade com as cidades que têm a insegurança e a incerteza como elementos definidores das relações que os assentados estabelecem com o Estado, os movimentos sociais, a sociedade mais ampla e, principalmente, com o mercado. A luta que se trava no assentamento real é orientada, sobretudo, pela busca de recursos financeiros para organizar a produção de modo a enfrentar a dinâmica do mercado. Inaugurou-se um outro momento no processo organizativo do Sepé Tiaraju quando a fragmentação das relações tem sido a marca fundamental. Ali tem sido possível visualizar não um retorno às comunidades tradicionais, mas as "comunidades estéticas" (Bauman, 2003), nas quais a afinidade é volátil e a união é vivida e sentida como se fosse real, mas os vínculos são de natureza superficial, perfunctória e transitória e não permitem firmar redes de responsabilidades éticas e compromissos de longo prazo. E, por conseguinte, identidades sociais que contribuam para consolidar o processo organizativo fundamentado na cooperação e na agroecologia, valores idealizados que hoje, de fato, perdem-se com facilidade na luta cotidiana para garantir a sobrevivência. Quebraram-se os "elos" comunitários? Que outros "elos" estão sendo criados? Este poderá ser um outro capítulo da "história lenta" do Sepé Tiaraju.

\section{Referências}

Associação Nacional de Cooperação Agrícola (2002). O que levar em conta para a organização do assentamento. São Paulo: Anca, Ministério do Meio Ambiente.

Bauman, Z. (2003). Comunidade: a busca por segurança no mundo atual. Rio de Janeiro: Zahar.

Bauman, Z. (2005). Identidade: entrevista a Benedetto Vecchi. Rio de Janeiro: Zahar.

Bourdieu, P. (1997). Compreender. In P. Boudieu et al. (Orgs.), A miséria do mundo (4⿳亠丷a ed., pp. 693-713). Petrópolis: Vozes.

Incra (2000). Projeto de Desenvolvimento Sustentável - PDS. Brasília: Ministério do Meio Ambiente.

Cândido, A. (1971). Parceiros do Rio Bonito: estudo sobre o caipira paulista e a transformação dos seus meios de vida (2 ed.). São Paulo: Duas Cidades.

Carvalho, H. M. (1999). A interação social e as possibilidades de coesão e de identidade sociais no cotidiano da vida social dos trabalhadores rurais nas áreas oficiais de reforma agrária no Brasil. Brasília: MPF/NEAD/IICA.

Carvalho, H. M. (2005). Política compensatória de assentamentos rurais como negação da reforma agrária. Revista Adusp, 34, 30-38.

Confederação das Cooperativas de Reforma Agrária do Brasil. (1998). Enfrentar os desafios da organização nos assentamentos. São Paulo: Concrab.

Confederação das Cooperativas de Reforma Agrária do Brasil. (2004). Novas formas de assentamento de reforma agrária: a experiência da Comuna da Terra. Cadernos de Cooperação Agrícola, Concrab/MST, 15. 
D'Incao, M. C. \& Roy, G. (1995). Nós cidadãos: aprendendo e ensinando a democracia. São Paulo: Paz e Terra.

Elias, N. \& Scotson, J. (2000). Os estabelecidos e os outsiders: sociologia das relações de poder a partir de uma pequena comunidade. Rio de Janeiro: Zahar.

Fernandes, B. N. (1999). MST: formação e territorialização (2 ${ }^{\underline{a}}$ ed.). São Paulo: Hucitec.

Ferrante, V. L. S. B. et al. (Orgs.). (1998). Assentamentos de trabalhadores rurais: a construção de um novo modo de vida em um campo de possibilidades e diversidades. Araraquara: Unesp.

Justo, M. G. (2005). "Exculhidos": ex-moradores de rua como camponeses num assentamento do MST. Tese de Doutorado, Faculdade de Filosofia, Letras e Ciências Humanas, Universidade de São Paulo, São Paulo.

L'Estoile, B. de \& Sigaud, L. (2006). Uma etnografia coletiva em terras pernambucanas. In B. de L'Estoile \& L. Sigaud (Orgs.), Ocupações de terra e transformações sociais: uma experiência de etnografia coletiva (pp. 7-28). Rio de Janeiro: FGV.

Matins, J. de S. (1994). O poder do atraso: ensaios de Sociologia da história lenta. São Paulo: Hucitec.

Oliveira, F. (1987). O elo perdido, classes e identidade de classe. São Paulo: Brasiliense.

Oliveira, B. A. M. (1996). Coprocol: um caso de contra-poder cooperativo? Dissertação de Mestrado, Programa de PósGraduação em Administração, Universidade Federal de Lavras, Lavras.

Perillo, S. R. \& Perdigão, M. de L. (2005). Percursos migratórios no estado de São Paulo: uma análise do período 1995-2000. São Paulo em Perspectiva, 19 (3), 97-109.

Pilatti, A. (1996). As contradições entre a gestão e a eficiência administrativa nas cooperativas de produção agropecuária. Monografia, Instituto Técnico de Capacitação e Pesquisa da Reforma Agrária, Veranópolis.

Queiroz, M. I. P. (1973). Bairros rurais paulistas: dinâmica das relações bairro rural-cidade. São Paulo: Duas Cidades.

Romano, J. O. (1994). Poder, valores e conflitos nos processos de organização no interior de assentamentos. In L. S. de Medeiros et al. (Orgs.), Assentamentos rurais: uma visão multidisciplinar (pp. 249-258). São Paulo: Unesp.

Rosim, L. H. (1997). Nas terras da usina, o fazer-se de um assentamento. Dissertação de Metrado, Faculdade de Filosofia e Letras, Universidade Estadual Paulista, Araraquara.

Scopinho, R. A. (2007). Sobre cooperação e cooperativismo em assentamentos rurais. Psicologia $\mathcal{E}$ Sociedade, 19 (número especial), 84-94.

Weil, S. (1996). Desenraizamento. In E. Bosi (Org.), Simone Weil: a condição operária e outros estudos sobre a opressão (2a ed.). Rio de Janeiro: Paz e Terra.

Whitaker, D. C. (2002). Sociologia rural: questões metodológicas emergentes. Presidente Venceslau, São Paulo: Letras a Margem.

Zimmerman, N. de C. (1994). Os desafios da organização interna de um assentamento rural. In L. S. Medeiros et al. (Orgs.), Assentamentos rurais: uma visão multidisciplinar (pp. 205-224). São Paulo: Unesp.

\section{Endereço para correspondência scopinho@ufscar.br}

